\title{
Orientation Sensitivity of Oxygen Evolution Reaction on Hematite
}

\author{
Xueqing Zhang ${ }^{\ddagger}$, Chonglong Cao ${ }^{\dagger *}$, Anja Bieberle-Hütter ${ }^{\star}$ \\ † School of Physics and Technology, University of Jinan, Jinan, Shandong, 250022, People's \\ Republic of China. \\ $\ddagger$ Electrochemical Materials and Interfaces, Dutch Institute for Fundamental Energy Research \\ (DIFFER), 5612AJ Eindhoven, the Netherlands
}

\begin{abstract}
:
The sensitivity of the surface orientation on photoelectrochemical water oxidation has recently been reported by experimental studies. However, a detailed theoretical understanding is still missing. Density functional theory + Hubbard $U(D F T+U)$ calculations are therefore carried out in order to investigate the oxygen evolution reaction (OER) on hematite $\left(\mathrm{Fe}_{2} \mathrm{O}_{3}\right)$ surfaces for five surface orientations, namely (100), (210), (101), (021) and (211). The free energies of four proton coupled electron transfer (PCET) steps and the OER overpotential were calculated and the trend in activity is analysed. For the (100) orientation, two adsorbate-adsorbate distances were studied. Interestingly, a very low overpotential of $0.52 \mathrm{~V}$ was found for the (100) surface with bridge site (adsorbate on a bridge of two Fe atoms) configuration benefited from adsorbate-adsorbate interactions.
\end{abstract}

\section{INTRODUCTION}

Photoelectrochemical (PEC) solar fuel production is a promising long-term technology pathway towards low greenhouse gas emissions. ${ }^{1-5}$ In the PEC process, water is split into hydrogen and oxygen with the help of sunlight and catalytically active semiconductors, the photoelectrodes.6, 7 The water oxidation at the photoelectrode is called oxygen evolution reaction (OER). In the field of PEC water splitting, the current research strongly focuses on the OER, because it accounts for most of the overpotential required to drive water splitting owing to the fourelectron process that is more complicated and energy required than the hydrogen evolution. ${ }^{6-9}$ Therefore, we focus in this paper on the OER and will study the OER on the photoelectrode material hematite $\left(\alpha-\mathrm{Fe}_{2} \mathrm{O}_{3}\right)$.
Hematite has emerged as a promising photoelectrode material for PEC water splitting and received much attention due to its suitable band gap of about $2.1 \mathrm{eV}$, an excellent chemical stability, its natural abundance, nontoxicity, and low cost. ${ }^{3,10,11}$ However, the high OER overpotential $^{3}$ limits its application as PEC material. ${ }^{12}$ It is therefore necessary to search for the most active hematite surface orientations towards OER for improving the solar-to-hydrogen conversion efficiency. The simulation of photoexcitation as the driving force of the water splitting reaction has only been demonstrated for small model systems so far. ${ }^{13,}{ }^{14}$ In most of the literature, water decomposition at the semiconductor surface is viewed in theoretical studies as an electrocatalytic process driven by the electrochemical potential.

Corresponding author : E-mail: sps_caocl@ujn.edu.cn 
Thus, we use the approach developed in the literature for investigation of electrochemical water oxidation. ${ }^{8}$

Strategies to increase the solar-to-fuelconversion efficiency have been proposed, such as controlling of thin film thickness, ${ }^{5,} 15$ doping,,$^{16}$ nanostructures, ${ }^{17}, 18$ and altering the surface orientation. ${ }^{19}$ Computational design at atomistic level can be achieved by the modern quantum chemical methods. $^{6-9}$ The effects of doping by $\mathrm{Ti}, \mathrm{Mn}, \mathrm{Co}, \mathrm{Ni}$, and Pt on the OER overpotential have been investigated by Liao et al. ${ }^{20}$ and Neufeld et al. ${ }^{21}$ Co and $\mathrm{Ni}$ were predicted as effective dopants for electrocatalysis of water. ${ }^{20}$ Nguyen et al. ${ }^{22}$, Hellman et al. ${ }^{23}$, and Toroker et al., ${ }^{24}$ investigated water oxidation on hematite (0001) with vacancies. ${ }^{24}$ More recently, Zhang et al. ${ }^{25}$ reported an overpotential of as low as $0.47 \mathrm{~V}$ for the hematite (110) surface with an oxygen vacancy concentration of 1.26 vacancies $/ \mathrm{nm}^{2}$. Neufeld and Toroker ${ }^{26}$ studied the role of an $\mathrm{Al}_{2} \mathrm{O}_{3}$ overlayer on $\mathrm{Fe}_{2} \mathrm{O}_{3}$ for water splitting. ${ }^{26}$ An improved water oxidation was found due to the decrease in the work function of $\alpha-\mathrm{Fe}_{2} \mathrm{O}_{3}$ upon $\alpha-\mathrm{Al}_{2} \mathrm{O}_{3}$ coverage that aids in extracting electrons during the water oxidation reaction. ${ }^{26}$

The search for active surface orientation has attracted many researchers recently. ${ }^{19}$ Kment et al. ${ }^{19}$ synthesised thin hematite films exhibiting controlled crystal orientation. The precise control of the synthetic conditions allows fabricating hematite photo-anodes exhibiting fully textured surfaces along (110) and (104) crystal planes. Very different photocurrents of 0.65 $\mathrm{mA} / \mathrm{cm}^{2}$ and $0.02 \mathrm{~mA} / \mathrm{cm}^{2}$ (at $1.55 \mathrm{~V}$ vs. RHE) were found for the (110) and the (104) orientations, respectively. ${ }^{19}$ The difference in performance was related to the different electron and hole mobilities and different surface termination of the different orientations. There is also a significant difference in onset potential of about $1.05 \mathrm{~V}$ vs. $1.55 \mathrm{~V}$ vs. RHE for (110) and (104), respectively.

More recently, Density Functional Theory (DFT) calculations by Zhang et al. ${ }^{25}$ showed that the (110) surface is more active than the (104) surface for the OER; however, the difference in overpotential is not large. This confirms the interpretations of Kment at al. that the large differences in performance between (110) and (104) surfaces are more related to the difference in photo-absorption and/or charge transport properties ${ }^{19}$ than to electrochemical activation. The anisotropic conductivity of hematite has also been demonstrated by other literature.27, 28 There are many other surface orientations in the synthesised hematite electrode. ${ }^{29-31}$ It is thus valuable to search for more active surface orientations for lowering the OER overpotential.

Significant theoretical contributions have been made to simulate the OER on the hematite (0001) surface. ${ }^{20-24,} 26, \quad 32-39$ Although the orientation dependence of OER activity for (110) and (104) surfaces has been investigated by Zhang et al., ${ }^{25}$ to our best knowledge, detailed computational analysing of the orientation dependent OER on hematite is still missing. From the intensity of $\mathrm{XRD}$, the most dominant surface orientations are (110) and (104). ${ }^{19,29}$ However, none of the surface orientations were found very promising for OER by DFT calculations. ${ }^{25}$ Therefore, the aim of this study is to calculate the overpotentials of less dominant surface orientations in order to find highly electrochemically active surfaces in the hematite structure.

With different surface orientations, there is a different density of atoms and voids the surface and also the electronic structure changes due to different distances and between the atoms. Therefore the species have different stability on the surfaces with different orientation. The relative stability of intermediate species varies the free energy steps. This will results in different OER activities. In this study, we focus on DFT $+U$ calculations of the OER activities of the five hematite surface orientations, (100), (210), (101), (021), and (211), respectively.

\section{METHOD}

Density Functional Theory (DFT) calculations have been performed using the ab-initio total-energy and molecular dynamics program VASP (Vienna Ab initio Simulation Package) developed by the Fakultät für Physik of the Universitat Wien. ${ }^{40-43}$ Since $\mathrm{Fe}_{2} \mathrm{O}_{3}$ contains highly correlated $3 d$ electrons, we chose the spin polarized $\mathrm{DFT}+\mathrm{U}$ formalism ${ }^{20}$ due to improper treatment of the d-electrons with standard DFT. The $U$ 
value of $4.3 \mathrm{eV}$ for Fe was derived in the literature ${ }^{20}$ and has been applied to many hematite systems..$^{9,21,25}$ The Perdew-Burke-Ernzerhof (PBE) XC functional ${ }^{44}$ and the projected augmented wave (PAW) ${ }^{40,45}$ potentials were used. We use in this study a solid-gas model similarly as in other OER studies of hematite. ${ }^{20-22}$ More computational details are provided in the supporting information.

\section{RESULTS AND DISCUSSION}

\section{Surface Structures and Electrochemical Model}

To study the orientation effect on the OER activity, five surface orientations were built from optimized bulk crystal structures, namely, (100), (210), (101), (021) and (211). The detailed information of the geometries can be found in the supporting information. The intermediate species can be adsorbed at two different adsorption sites, terminal (an $\mathrm{O}$ is bonded to one Fe atom) or bridge (an $\mathrm{O}$ is bonded to two Fe atoms) site. Detailed information about these two adsorption sites is given in ref. ${ }^{25}$ In Figure 1, the (100) hematite surface is shown as an example with the free surface site $\left(^{*}\right)$ and the adsorbed intermediate species, $\mathrm{OH}, \mathrm{O}$, and $\mathrm{OOH}$, respectively, at the bridge site. The active sites are indicated by green circles.

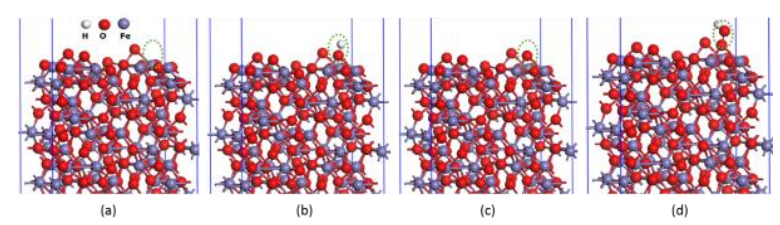

Figure 1. Examples of the (100) hematite surfaces with different intermediate species adsorbed at the bridge site; free surface site * (a), $\mathrm{OH}(\mathrm{b}), \mathrm{O}(\mathrm{c}), \mathrm{OOH}(\mathrm{d})$, respectively. The dashed lines (light green) show the position of the active site.

Several reaction mechanisms were proposed for the OER on metal oxide surfaces in the literature. ${ }^{7}$ In our study, we follow the widely-used OER mechanism proposed by Rossmeisl et al. ${ }^{8}$ This mechanism consists of four proton-coupled electron transfer (PCET) steps as illustrated by eq.(1-4). In this mechanism, the water adsorption and first PCET step have been combined. In this first combined step, the overall reaction is the adsorption and dissociation of a water molecule over a free site. Liao et al. ${ }^{20}$ included the water adsorption step separately in their studies on hematite (0001) surface and found that much less energy is required for the adsorption than for the electrochemical steps; water adsorption is therefore also not considered separately in this study. This mechanism has become very popular and has been shown to predict trends for the OER quite well. 4, 7, 21, 46-50 The effect of a bias on all states involving an electron in the electrode is included by shifting the energy of this state by $\Delta \mathrm{Gu}=-\mathrm{eU}$, where $\mathrm{U}$ is the electrode potential relative to the standard hydrogen electrode. ${ }^{8}$ The four PCET steps are,

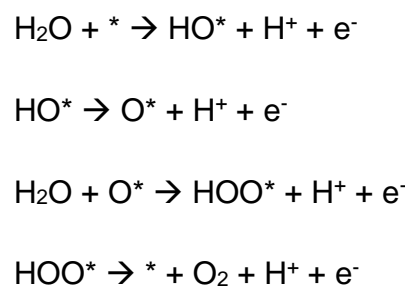

The reaction free energies under an applied potential $\mathrm{U}$ are calculated as follows.

$$
\begin{gathered}
\Delta G_{1}=E(* \mathrm{OH})-E(*)-E_{\mathrm{H}_{2} \mathrm{O}}+\frac{1}{2} E_{\mathrm{H}_{2}}+(\Delta Z P E- \\
T \Delta S)_{1}-e U
\end{gathered}
$$

$$
\Delta G_{2}=E(* 0)-E(* \mathrm{OH})+\frac{1}{2} E_{\mathrm{H}_{2}}+(\Delta Z P E-T \Delta S)_{2}-e U
$$

$$
\begin{gathered}
\Delta G_{3}=E(* \mathrm{OOH})-E(* 0)-E_{\mathrm{H}_{2} \mathrm{O}}+\frac{1}{2} E_{\mathrm{H}_{2}}+(\Delta Z P E- \\
T \Delta S)_{3}-e U \\
\Delta G_{4}=E(*)-E(* \mathrm{OOH})+E_{\mathrm{O}_{2}}+\frac{1}{2} E_{\mathrm{H}_{2}}+(\Delta Z P E- \\
T \Delta S)_{4}-e U
\end{gathered}
$$

$\Delta \mathrm{G}_{\mathrm{n}}$ are the free energy steps corresponding to the reactions shown in eq. (1-4). $\triangle Z P E$ is the difference in zero point energies due to the reaction, $\Delta S$ is the change in entropy. More details on the calculation of the energies is given in the supporting information.

\section{Surface Orientations}

Figure 2 shows the free energy profiles of the four PCET steps for the five surface orientations, (100) on bridge site, (210) on terminal site, (101) on bridge site, (021) on bridge site, and (211) on terminal site, respectively, which were calculated by using the approach developed by Rossmeisl and Norskov et al. ${ }^{8}$ 
The choice of the active site is based on the stability of the intermediate species and availability of the active site. The bridge site is usually more stable. However, this requires both $\mathrm{Fe}$ atoms that form the bridge available simultaneously. There are more available reaction site if the terminal site is stable. Thus, the first choice is a terminal site. If the terminal site is not stable, then the we choose bridge site. In Figure 2 (a), the free energy profiles of hematite (100) at three different potentials $(U=0, U=1.23$, and $U=2.02 \mathrm{~V})$ are shown. At $U=0 \mathrm{~V}$, all steps are uphill. To drive the OER process, each step must be supplied with a sufficient applied voltage. The effect of a bias is included by shifting the energy of this step by -eU. At standard equilibrium potential for oxygen evolution $(U=1.23 \mathrm{~V})$, some of the steps become downhill but some still remain uphill, i.e. the $\mathrm{O}$ formation $\left(\Delta \mathrm{G}_{2}\right)$ and the $\mathrm{OOH}$ formation $\left(\Delta \mathrm{G}_{3}\right)$. In order to split water and produce $\mathrm{O}_{2}$, all steps need to be downhill; hence, a higher potential than the ideal $1.23 \mathrm{~V}$ have to be applied. This potential is called the overpotential. The largest step is the $\mathrm{OOH}$ formation $\left(\Delta \mathrm{G}_{3}=2.02 \mathrm{~V}\right)$. Thus, at $\mathrm{U}=2.02 \mathrm{~V}, \Delta \mathrm{G}_{3}=0$; all the other steps became downhill, which means that an electrochemical overpotential $(\eta)$ of $0.79 \vee(\eta=2.02$. $1.23 \mathrm{~V})$ is found for this surface. In general, the overpotential for a specific surface is calculated as follows

$$
\eta=\frac{\max \left[\Delta G_{1}, \Delta G_{2}, \Delta G_{3}, \Delta G_{4}\right]}{e}-1.23[\mathrm{~V}]
$$

The free energies of the intermediates on terminal site of hematite (210) surface at three different potentials $(U=0, U=1.23$, and $U=2.03 \mathrm{~V})$ are shown in Figure 2 (b). The potential determining step is the formation of $O$ with $\Delta G_{2}=2.03 \mathrm{~V}$. The overpotential is thus $0.80 \mathrm{~V}$, which is similar to that of the (100) surface.

The free energies of the intermediates on hematite (101), (021) and (211) surfaces at different potentials are shown in Figure 2 (c-e). These surfaces have the common potential determining step (formation of $O)$ and higher overpotential than (100) and (210) surfaces, $0.94 \mathrm{~V}, 1.00 \mathrm{~V}$ and $1.47 \mathrm{~V}$ for (101), (021) and (211) surfaces respectively. Therefore, the calculations suggest that hematite (101), (021) and (211) surfaces are not active for OER.
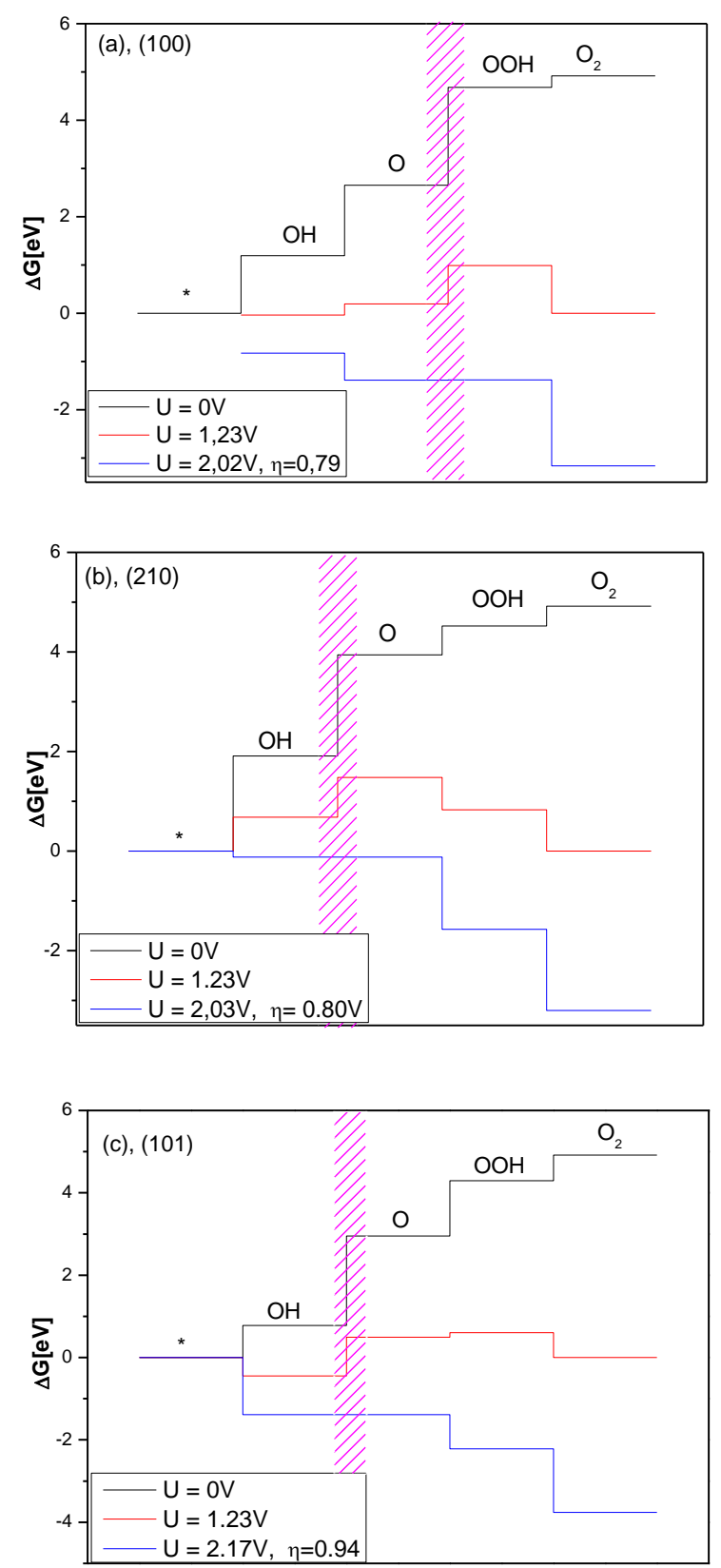

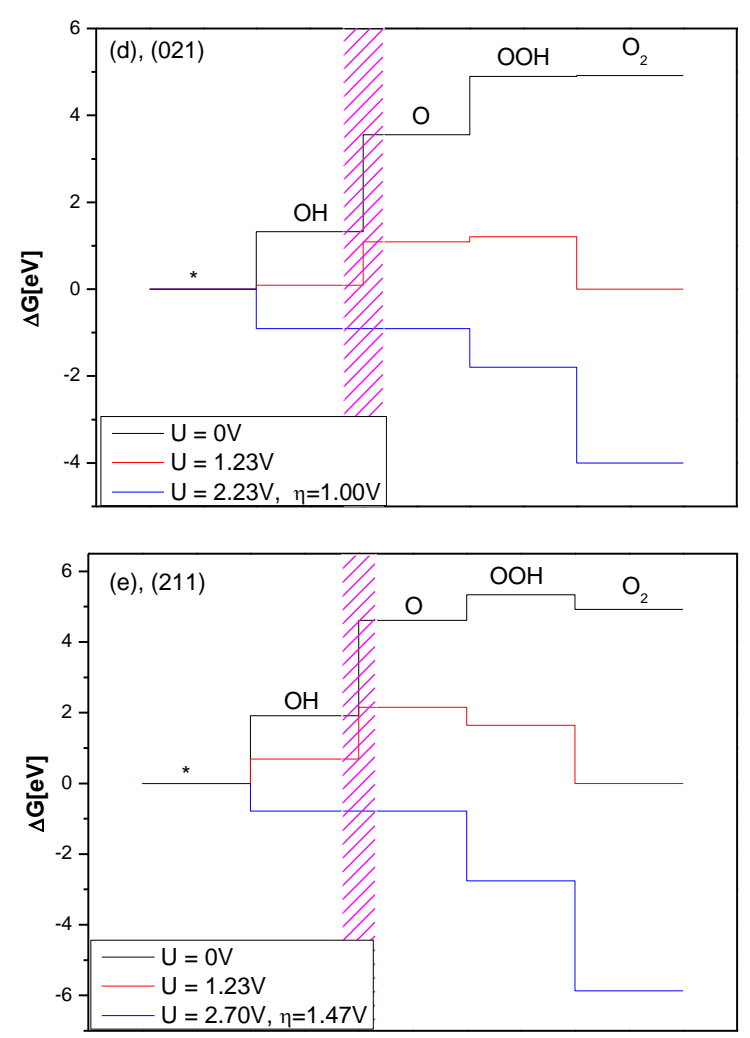

Figure 2. The free energy diagrams of the intermediates on hematite a) (100), b) (210), c) (101), d) (021), and e) (211) at different potentials $U=0 \mathrm{~V}, \mathrm{U}=1.23 \mathrm{~V}$, and $\mathrm{U}$ $=2.02 \mathrm{~V}, 2.03 \mathrm{~V}, 2.17 \mathrm{~V}, 2.23 \mathrm{~V}$ and $2.70 \mathrm{~V}$ for (100), (210), (101), (021), and (211). The different potentials are applied due to different overpotentials for these surfaces. The purple shaded fields are marked for guiding the eyes for the potential determining steps.

Hematite (100) and (210) surfaces are similar in the overpotential with $(110)$ surface $(\eta=0.79 \mathrm{~V})$, which was studied recently in the literature. ${ }^{25}$ Therefore, we compare their OER free energy profiles in Figure 3. The potential determining step for the (100) surface is the $\mathrm{OOH}$ formation. However, the $\mathrm{O}$ formation is potential determining for (110) and (210) surfaces. Thus, the relative stability of intermediate species are different although the overpotentials are similar. From Figure 3, we can see that the largest difference between the three orientations is the formation of $\mathrm{O}$. $\mathrm{O}$ is significantly stabilized on (100) surface, which results in a large $\Delta G_{3}$, meaning the $\mathrm{OOH}$ formation is potential determining. Both $\mathrm{OH}$ and $\mathrm{O}$ are destabilised on (210) and (110) surfaces with respect to the (100) surface. Thus, their potential determining step is the same (the $O$ formation) and the overpotentials are similar $(0.80$ and $0.79 \mathrm{~V})$.

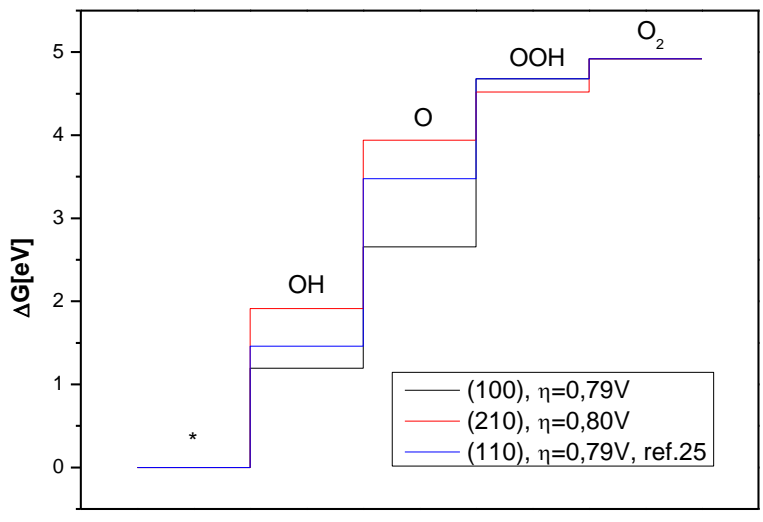

Figure 3. Free energy diagram of the intermediates on hematite (100), (210), and (110) surfaces at $U=0$. For comparison, the free energies of OER species on hematite (110) surface from the literature ${ }^{25}$ are included.

\section{Adsorbate-adsorbate Interaction}

So far, the (100) surface has been found more active than the other four surface orientations studied in this work. We choose (100) surface to study the effect of adsorbate-adsorbate interaction on OER activity. In the case of the (100) surface the adsorbate distance was $10.19 \AA$ (Figure 4 (a)). No interaction of the adsorbates at this long distance is expected. We reduced the cell of (100) by half and name this geometry (100) $\llcorner$ (Figure 4 (b)). The adsorbate-adsorbate distance is 5.10 for $(100)\llcorner$. The free energy profile of $(100)\llcorner$ at different potentials $(U=0,1.23$ and $1.75 \mathrm{~V})$ are calculated in Figure 5 (a). The potential determining step is the $\mathrm{O}$ formation with an overpotential of $0.52 \mathrm{~V}$. The OER activity of (100) and (100) L are compared in Figure $5(b)$. It is found that the overpotential is $0.27 \mathrm{~V}$ lower than the overpotential for the (100) surface $(0.79$ V). This strongly indicates the influence of adsorbateadsorbate interactions. The same trend was found in the literature. ${ }^{20}$ Liao et al. compared the OER at $(1 \times 1)$ and $(2 \times 2)$ slabs of hematite $(0001)$ surface. The authors found a difference of $0.2 \mathrm{~V}$ in overpotential, $1.82 \mathrm{vs}$. 2.02 $\mathrm{V}$ for $(1 \times 1)$ and $(2 \times 2)$, respectively. The lateral cell size is also $5.10 \AA$ for the $(1 \times 1)$ slab. This implies that the adsorbate-adsorbate interaction of adsorbates for OER becomes important within $5.10 \AA$. The larger 
molecules $(\mathrm{OH}$ and $\mathrm{OOH})$ contribute more to the adsorbate-adsorbate interaction. Therefore, the change in the energy of $\mathrm{O}$ is very small compared to $\mathrm{OH}$ and $\mathrm{OOH}$ as shown in Figure 5 (b). Both $\mathrm{OH}$ and $\mathrm{OOH}$ states of $(100)\llcorner$ are shifted to lower free energies with respect to (100) surface. This increases $\Delta G_{2}$ and decreases $\Delta G_{3}$ relatively to (100) surface. Therefore, the potential determining steps are different for the two surfaces. It is noteworthy that the difference between $\Delta \mathrm{G}_{2}(1.75 \mathrm{~V})$ and $\Delta \mathrm{G}_{3}(1.64 \mathrm{~V})$ of $(100) \mathrm{L}$ is small. It was found that the binding energies $\Delta \mathrm{GoOH}$ and $\Delta \mathrm{GoH}$ generally differ by about $3.2 \mathrm{eV}\left(\Delta \mathrm{G}_{2}+\Delta \mathrm{G}_{3}\right)$ for both metals and some oxides. ${ }^{4,51}$ Therefore, an optimal balance between $\Delta \mathrm{G}_{2}$ and $\Delta G_{3}$ reduces the overpotential and thus makes (100) L surface active for OER. The adsorbate-adsorbate interaction favours the OER by stabilizing of both $\mathrm{OH}$ and $\mathrm{OOH}$. In the real system, the neighbouring sites of the reaction site are supposed to be occupied by adsorbates. We expect the adsorbate-adsorbate interaction. Therefore, it should be considered in the simulations of the OER.

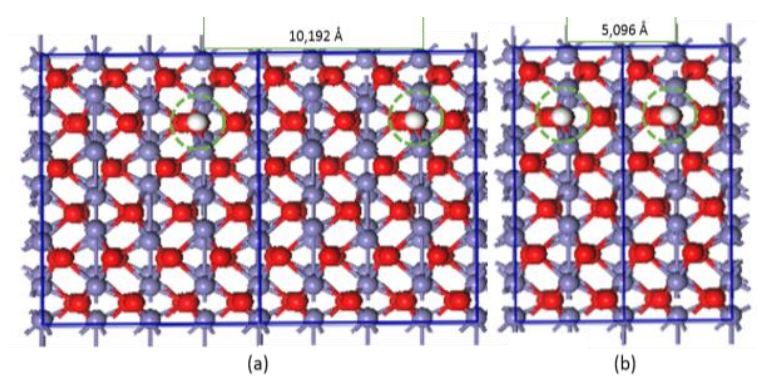

Figure 4. Top view of geometries of two simulation cells of a) the (100) surfaces and b) the (100) L surface. The active sites are indicated by circles. The distance between two adsorbate site is indicated.
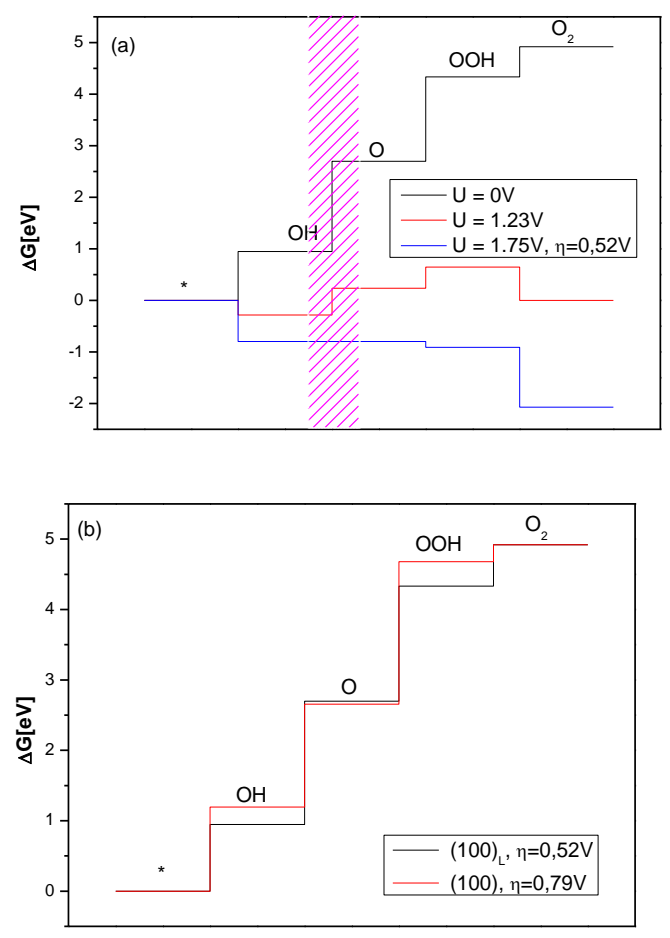

Figure 5. (a) The free energies of the intermediates on hematite $(100)\llcorner$ at three different potentials $(U=0, U=$ 1.23 , and $U=1.75 \mathrm{~V})$. The region marked purple shows the potential determining step, i.e., from $\mathrm{OH}$ to $\mathrm{O}$. (b) Comparison of free energies between (100) $\llcorner$ and (100).

\section{Overpotential Trend}

In Table 1, we summarize the calculated overpotential and the potential determining reactions of the systems studied in this work and compare it to the literature. ${ }^{20,22,25}$ All calculations were performed with a similar level of theory. We did not refer to experimental values, because a direct quantitative comparison between the theoretical and experimental overpotentials cannot be made due to limitations on both sides as indicated by Valdes et al. ${ }^{4}$ and Man et al. ${ }^{52}$ Theoretical calculations usually do not take into account effects of electric field and surface charges. Also, proton transfer barriers are not included. All these effects are very important for the absolute rate of the reaction. ${ }^{8}$ Furthermore, the experiments were performed using electrodes with oxide nanoparticles, for which the effective surface area is often unknown or not reported. ${ }^{52}$ Therefore, we study the trend in the OER activities here. The overpotential increase from above to below in Table 1. We can see that the overpotential changes sensitively with the orientation. The lowest overpotential of $0.52 \mathrm{~V}$ is found for bridge site (100) $\mathrm{L}$ 
surface, which is more active for OER than the other surfaces. The highest overpotential is found for (211) surface $(1.47 \mathrm{~V})$. For most of the systems, the potential determining reaction is the formation of $O$. In the experiment, the (110) and (104) are the most prominent orientations. ${ }^{19}$ The (110) was found more active than the (104) orientation. ${ }^{19,} 25$ Interestingly, we found that (100) orientation is also active for OER.

Table 1. Summary of OER overpotentials and potential determining reactions for different orientations of hematite surfaces. The overpotential decrease from above to below. The surfaces are O-terminated unless indicated.

\begin{tabular}{|c|c|c|}
\hline Surface sites & Overpotential & \begin{tabular}{|l} 
Potential \\
determining \\
reaction \\
\end{tabular} \\
\hline$(100)\llcorner$, bridge & $0.52 \mathrm{~V}$ & Formation of $\mathrm{O}$ \\
\hline $\begin{array}{l}(0001), \text { bridge, } \mathrm{OH}- \\
\text { terminated }^{20}\end{array}$ & $0.77 \mathrm{~V}$ & Formation of $\mathrm{O}$ \\
\hline (110), bridge ref. ${ }^{25}$ & $0.78 \mathrm{~V}$ & Formation of $\mathrm{O}$ \\
\hline (110), terminal ref. ${ }^{25}$ & $0.79 \mathrm{~V}$ & \multirow{2}{*}{$\begin{array}{l}\text { Formation of } \mathrm{O} \\
\text { Formation of } \\
\mathrm{OOH}\end{array}$} \\
\hline (100), bridge & $0.79 \mathrm{~V}$ & \\
\hline (210), terminal & $0.80 \mathrm{~V}$ & Formation of $\mathrm{O}$ \\
\hline (0001), bridge 22 & $0.82 \mathrm{~V}$ & Formation of $\mathrm{O}$ \\
\hline (104), bridge ref. ${ }^{25}$ & $0.92 \mathrm{~V}$ & Formation of $\mathrm{O}$ \\
\hline (101), bridge & $0.94 \mathrm{~V}$ & Formation of $\mathrm{O}$ \\
\hline (021), bridge & $1.00 \mathrm{~V}$ & Formation of $\mathrm{O}$ \\
\hline (104), terminal ref. ${ }^{25}$ & $1.01 \mathrm{~V}$ & Formation of $\mathrm{O}$ \\
\hline (211), terminal & $1.47 \mathrm{~V}$ & Formation of $\mathrm{O}$ \\
\hline
\end{tabular}

Figure 6 shows the activity trend for oxygen evolution according to the six hematite surfaces which were studied. The overpotential is plotted as negative value as a function of the energy step $\Delta \mathrm{G}_{\mathrm{o}}-\Delta \mathrm{G}_{\mathrm{oH}}$. An overpotential of zero signifies that the reaction mechanism is not electrochemically hindered. With the data simulated in this study, a volcano plot is found with the $(100)\llcorner$ surface as the top of the volcano. This means that the (100) $\llcorner$ surface shows the best OER activity with an overpotential as low as $0.52 \mathrm{~V}$. For all surface on the right side of the volcano, the $\mathrm{O}$ formation is potential determining. Only the (100) surface is located at the left side of the volcano plot. The $\mathrm{OOH}$ formation is the potential determining step. The literature values are shown in the marked region, ${ }^{20,23,25}$ which is at the right side, indicating the $\mathrm{O}$ formation potential determining.

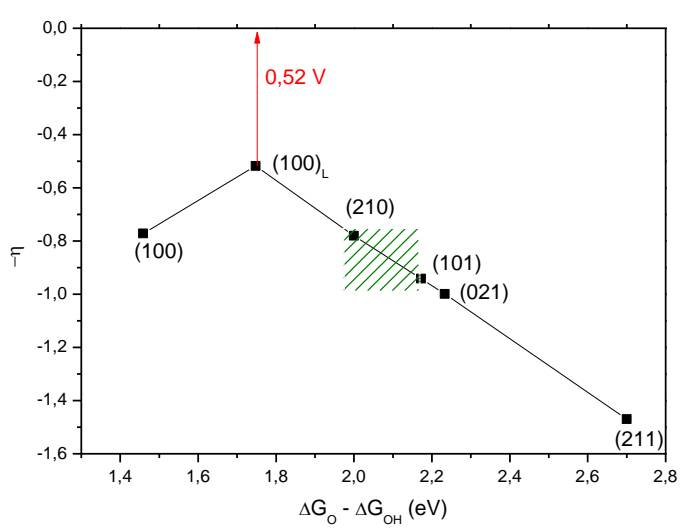

Figure 6. Volcano plot of the activity trends for oxygen evolution on hematite surfaces. The negative value of calculated overpotential is plotted against the energy step of $\Delta \mathrm{Go}_{\mathrm{o}} \Delta \mathrm{GoH}$. The literature values ${ }^{20,23,25}$ are located in the marked region. The red arrow shows the difference between the peak of the volcano (the lowest overpotential) and the zero line (ideal catalyst).

\section{Stability vs. Activity}

We discuss in this section the stability of the five surfaces that were considered before by comparing their surface energies. Surface energy is the energy required to create one unit of surface area, which is a function of the difference between the energies of before and after the surface formation. The surface energy $\gamma$ is calculated from the following equation, ${ }^{53,54}$

$$
\gamma=\frac{E_{\text {slab }}-N \times E_{\text {bulk }}}{2 A}
$$

Where $E_{\text {slab }}$ is the total energy of slab (the slab includes the molecular geometry of the surface created and vacuum). $N$ is the number of $\mathrm{Fe}_{2} \mathrm{O}_{3}$ units in the slab. $E_{\text {bulk }}$ is the bulk energy per $\mathrm{Fe}_{2} \mathrm{O}_{3}$ unit. $A$ is the exposed surface area. The slab has two surfaces and they are of the same type which is reflected by the number 2 in the denominator. ${ }^{54}$ Table 2 lists the surface orientations calculated in this study with the calculated surface energies. The (100) surface has the lowest surface energy and is therefore the most stable surface. It is also the most active surface for OER as discussed above. However, in general, the stability does not follow the OER activity trend. The (210) surface is more active 
than the (211), (021) and (101) surfaces according to Figure 6, however it is not stable due to a high surface energy. The surface energy of $1.72 \mathrm{~J} / \mathrm{m}^{2}$ of the (100) surface is comparable with that of $\mathrm{Fe}_{2} \mathrm{O}_{3}$ (0001) surface, which is commonly believed as a stable surface. ${ }^{20,54}$ Wasserman et al. ${ }^{54}$ reported the surface energies of $1.64 \mathrm{~J} / \mathrm{m}^{2}$ and $2.00 \mathrm{~J} / \mathrm{m}^{2}$ for (0001) and (012) surfaces, respectively. We can conclude that the (100) surface is the most stable and most active surface for OER among the five surfaces studied in this work.

Table 2. Surface energies of the different surface orientations studied in this work.

\begin{tabular}{ll|}
\hline Surface orientation & Surface energy $\left(\mathrm{J} / \mathrm{m}^{2}\right)$ \\
\hline \hline$(100)$ & 1.72 \\
$(211)$ & 1.99 \\
$(210)$ & 2.30 \\
$(021)$ & 2.42 \\
$(101)$ & 2.67 \\
\hline \hline
\end{tabular}

\section{CONCLUSIONS}

$\mathrm{DFT}+U$ calculations have been performed to investigate the OER activities depending on the orientation of $\mathrm{Fe}_{2} \mathrm{O}_{3}$ surfaces. Five different hematite surface orientations have been studied. The calculated results show that the difference between the lowest and highest overpotential is $0.95 \mathrm{~V}$. This proves a strong sensitivity of the OER activity on the surface orientation. The surface energies of the five surface are calculated. The (100) and (210) surfaces are more active than the other surfaces studied due to lower OER overpotentials, $0.79 \mathrm{~V}$ and $0.80 \mathrm{~V}$, respectively, however the (210) surface is less stable due to a higher surface energy. The (100) surface is the most stable and most active surface for OER among the five surfaces considered in this study. The $O$ formation is the potential determining step for most of the studied hematite surfaces. The lowest overpotential of $0.52 \mathrm{~V}$ is found for $(100) \mathrm{L}$ benefited from adsorbate-adsorbate interactions. The adsorbate-adsorbate interactions of adsorbed OER intermediate species play an important role within 5.10 $\AA$. Therefore, the future calculations of OER should consider the adsorbate-adsorbate interactions.

\section{ASSOCIATED CONTENT}

\section{Supporting Information}

The Supporting Information is available free of charge on the ACS Publications website.

Details on the molecular structures and computational details.

\section{AUTHOR INFORMATION}

Corresponding Author

*Electronic mail: sps_caocl@ujn.edu.cn

\section{Notes}

The authors declare no competing financial interest.

\section{ACKNOWLEDGMENTS}

Zhang and Bieberle-Hütter acknowledge the financial support from NWO (FOM program nr. 147 " $\mathrm{CO}_{2}$ neutral fuels") for carrying out this study. Cao acknowledge the financial support from the Natural Science Foundation of Shandong Province (Grant No. ZR2015AL020). Supercomputing facilities of the Dutch national supercomputers SURFsara/Lisa and Cartesius are acknowledged. 


\section{REFERENCES}

1. M. Gratzel, Nature, 2001, 414, 338-344.

2. R. van de Krol, Y. Liang and J. Schoonman, J. Mater. Chem., 2008, 18, 2311-2320.

3. K. Sivula, F. Le Formal and M. Grätzel, ChemSusChem, 2011, 4, 432-449.

4. A. Valdes, J. Brillet, M. Gratzel, H. Gudmundsdottir, H. A. Hansen, H. Jonsson, P. Klupfel, G.-J. Kroes, F. Le Formal, I. C. Man, R. S. Martins, J. K. Norskov, J. Rossmeisl, K. Sivula, A. Vojvodic and M. Zach, PCCP, 2012, 14, 49-70.

5. F. Le Formal, M. Grätzel and K. Sivula, Adv. Funct. Mater., 2010, 20, 1099-1107.

6. A. V. Akimov, A. J. Neukirch and O. V. Prezhdo, Chem. Rev., 2013, 113, 4496-4565.

7. X. Zhang and A. Bieberle-Hütter, ChemSusChem, 2016, 9, 1223-1242.

8. J. Rossmeisl, Z. W. Qu, H. Zhu, G. J. Kroes and J. K. Nørskov, J. Electroanal. Chem., 2007, 607, 83-98.

9. P. Liao and E. A. Carter, Chem. Soc. Rev., 2013, 42, 2401-2422.

10. L. Jia, K. Harbauer, P. Bogdanoff, I. Herrmann-Geppert, A. Ramirez, R. van de Krol and S. Fiechter, Journal of Materials Chemistry A, 2014, 2, 20196-20202.

11. F. Le Formal, E. Pastor, S. D. Tilley, C. A. Mesa, S. R. Pendlebury, M. Grätzel and J. R. Durrant, J. Am. Chem. Soc., 2015, 137, 6629-6637.

12. M. G. Walter, E. L. Warren, J. R. McKone, S. W. Boettcher, Q. Mi, E. A. Santori and N. S. Lewis, Chem. Rev., 2010, 110, 6446-6473.

13. A. Kazaryan, R. van Santen and E. J. Baerends, PCCP, 2015, 17, 20308-20321.

14. E. Berardo, H.-S. Hu, S. A. Shevlin, S. M. Woodley, K. Kowalski and M. A. Zwijnenburg, Journal of Chemical Theory and Computation, 2014, 10, 1189-1199.

15. O. Zandi, J. A. Beardslee and T. Hamann, The Journal of Physical Chemistry C, 2014, 118, 1649416503.

16. X. Zhang, H. Li, S. Wang, F.-R. F. Fan and A. J. Bard, The Journal of Physical Chemistry C, 2014, 118, 16842-16850.

17. J. Brillet, M. Grätzel and K. Sivula, Nano Lett., 2010, 10, 4155-4160.

18. T. K. Townsend, E. M. Sabio, N. D. Browning and F. E. Osterloh, Energy \& Environmental Science, 2011, 4, 4270-4275.

19. S. Kment, P. Schmuki, Z. Hubicka, L. Machala, R. Kirchgeorg, N. Liu, L. Wang, K. Lee, J. Olejnicek, M. Cada, I. Gregora and R. Zboril, ACS Nano, 2015, 9, 7113-7123.

20. P. Liao, J. A. Keith and E. A. Carter, J. Am. Chem. Soc., 2012, 134, 13296-13309.

21. O. Neufeld and M. C. Toroker, The Journal of Physical Chemistry C, 2015, 119, 5836-5847.

22. M.-T. Nguyen, S. Piccinin, N. Seriani and R. Gebauer, ACS Catalysis, 2015, 5, 715-721.

23. A. Hellman, B. landolo, B. Wickman, H. Grönbeck and J. Baltrusaitis, Surf. Sci., 2015, 640, 4549.

24. M. C. Toroker, The Journal of Physical Chemistry C, 2014, 118, 23162-23167.

25. X. Zhang, P. Klaver, R. van Santen, M. C. M. van de Sanden and A. Bieberle-Hütter, The Journal of Physical Chemistry C, 2016, 120, 18201-18208.

26. O. Neufeld, N. Yatom and M. Caspary Toroker, ACS Catalysis, 2015, 5, 7237-7243.

27. A. Kleiman-Shwarsctein, Y.-S. Hu, A. J. Forman, G. D. Stucky and E. W. McFarland, The Journal of Physical Chemistry C, 2008, 112, 15900-15907.

28. M.-C. e. a. Huang, Vacuum, 2016, 129, 111-114.

29. S. C. Warren, K. Voïtchovsky, H. Dotan, C. M. Leroy, M. Cornuz, F. Stellacci, C. Hébert, A. Rothschild and M. Grätzel, Nat Mater, 2013, 12, 842-849.

30. J. Y. T. Chan, S. Y. Ang, E. Y. Ye, M. Sullivan, J. Zhang and M. Lin, PCCP, 2015, 17, 25333-25341.

31. G. S. Parkinson, Surf. Sci. Rep., 2016, 71, 272-365.

32. P. Liao, M. C. Toroker and E. A. Carter, Nano Lett., 2011, 11, 1775-1781. 
33. M.-T. Nguyen, N. Seriani, S. Piccinin and R. Gebauer, The Journal of Chemical Physics, 2014, 140, 064703.

34. M.-T. Nguyen, M. Farnesi Camellone and R. Gebauer, The Journal of Chemical Physics, 2015, 143, 034704.

35. O. Neufeld and M. C. Toroker, PCCP, 2015, 17, 24129-24137.

36. M.-T. Nguyen, N. Seriani and R. Gebauer, ChemPhysChem, 2014, 15, 3136-3136.

37. N. Yatom, O. Neufeld and M. Caspary Toroker, The Journal of Physical Chemistry C, 2015, 119, 24789-24795.

38. K. Ulman, M.-T. Nguyen, N. Seriani and R. Gebauer, The Journal of Chemical Physics, 2016, 144, 094701.

39. N. Yatom and M. Toroker, Molecules, 2015, 20, 19668.

40. G. Kresse and D. Joubert, Physical Review B, 1999, 59, 1758-1775.

41. O. Bengone, M. Alouani, P. Blöchl and J. Hugel, Physical Review B, 2000, 62, 16392-16401.

42. G. Kresse and J. Furthmüller, Comput. Mater. Sci., 1996, 6, 15-50.

43. G. Kresse and J. Furthmüller, Physical Review B, 1996, 54, 11169-11186.

44. J. P. Perdew, K. Burke and M. Ernzerhof, Phys. Rev. Lett., 1996, 77, 3865-3868.

45. P. E. Blöchl, Physical Review B, 1994, 50, 17953-17979.

46. R. Frydendal, M. Busch, N. B. Halck, E. A. Paoli, P. Krtil, I. Chorkendorff and J. Rossmeisl, ChemCatChem, 2015, 7, 149-154.

47. F. Calle-Vallejo, O. A. Díaz-Morales, M. J. Kolb and M. T. M. Koper, ACS Catalysis, 2015, 5, 869873.

48. X. Zhou, E. J. M. Hensen, R. A. van Santen and C. Li, Chemistry - A European Journal, 2014, 20, 6915-6926.

49. X. Zhou, H. Dong and A.-M. Ren, PCCP, 2016, 18, 11111-11119.

50. J. Yang, H. An, X. Zhou and C. Li, The Journal of Physical Chemistry C, 2015, 119, 18487-18494.

51. M. T. M. Koper, J. Electroanal. Chem., 2011, 660, 254-260.

52. I. C. Man, H.-Y. Su, F. Calle-Vallejo, H. A. Hansen, J. I. Martínez, N. G. Inoglu, J. Kitchin, T. F. Jaramillo, J. K. Nørskov and J. Rossmeisl, ChemCatChem, 2011, 3, 1159-1165.

53. L. Vitos, A. V. Ruban, H. L. Skriver and J. Kollár, Surf. Sci., 1998, 411, 186-202.

54. E. Wasserman, J. R. Rustad, A. R. Felmy, B. P. Hay and J. W. Halley, Surf. Sci., 1997, 385, 217239. 